\title{
Adhesion molecules in human trophoblast - a review. I. Villous trophoblast.
}

DOI:

10.1016/j.placenta.2008.12.001

\section{Document Version}

Accepted author manuscript

Link to publication record in Manchester Research Explorer

\section{Citation for published version (APA):}

Aplin, J. D., Jones, C. J. P., \& Harris, L. K. (2009). Adhesion molecules in human trophoblast - a review. I. Villous trophoblast. Placenta, 30(4), 293-298. https://doi.org/10.1016/j.placenta.2008.12.001

\section{Published in:}

Placenta

\section{Citing this paper}

Please note that where the full-text provided on Manchester Research Explorer is the Author Accepted Manuscript or Proof version this may differ from the final Published version. If citing, it is advised that you check and use the publisher's definitive version.

\section{General rights}

Copyright and moral rights for the publications made accessible in the Research Explorer are retained by the authors and/or other copyright owners and it is a condition of accessing publications that users recognise and abide by the legal requirements associated with these rights.

\section{Takedown policy}

If you believe that this document breaches copyright please refer to the University of Manchester's Takedown Procedures [http://man.ac.uk/04Y6Bo] or contact uml.scholarlycommunications@manchester.ac.uk providing relevant details, so we can investigate your claim.

\section{OPEN ACCESS}




\title{
Adhesion molecules in human trophoblast - A review I Villous trophoblast
}

\author{
JD Aplin*, CJP Jones and LK Harris \\ Maternal and Fetal Health Research Group, University of Manchester, St Mary's Hospital, \\ Manchester M13 OJH, UK
}

Keywords: trophoblast, adhesion molecule, junction, differentiation, ultrastructure Running title: Adhesion molecules in villous trophoblast

* Corresponding author

Email address: john.aplin@manchester.ac.uk 


\begin{abstract}
In the placental villus, cells attach to basement membrane via integrin a6 $\beta 4$ and adhere both laterally and apically to their neighbours. The most prominent adhesive specialisation seen in the electron microscope is the desmosome, which connects cytotrophoblast cells (CTB) laterally and also contributes to the attachment of CTB to the overlying syncytium. However, numerous cadherins and other junctional proteins are also present in the corresponding plasma membrane domains, indicating a multiplicity of adhesive interactions. Integrins, tight junction components and cadherins are all found in the syncytial microvillous membrane, perhaps reflecting its ability to form intersyncytial bridges. There is a wide gulf to be filled between molecular anatomy and functional studies, with much to be learned about the role of adhesion molecules in regulating villous epithelial integrity, homeostasis and growth.
\end{abstract}




\section{Introduction}

Villous cytotrophoblasts (CTB) are committed progenitor cells that occupy a niche between the syncytiotrophoblast (STB) and the villous basement membrane [1]. In early gestation they form an almost continuous monolayer (Figure 1a, 2b). With advancing villous development, as the density of CTB progenitor cells declines, there is a change in which lateral CTB-CTB adhesion is replaced by CTB-STB adhesion [1]. In addition, sites are seen at which syncytial microvillous membranes (MVMs; Figure 1) make adhesive contact (Figure $2 a)$, thus bridging the intervillous space $[2,3]$. Formation of such bridges increases during gestation [4], and may stabilise the placenta (Figure 1b). At term, villous CTB maintain contact with one another by extending long processes laterally across the basement membrane [5]. Thus adhesive contacts are required with the basement membrane, overlying STB and, to a varying extent, adjacent CTB [1]. In addition adhesion occurs to a fibrinoid repair matrix that appears at sites of damage to the epithelium[6].

Early morphological studies of the placenta indicated the presence of adhesive structures sufficiently large in size to be recognisable by transmission or freeze fracture electron microscopy. These junctional specialisations have been described as zonulae and maculae occludentes and maculae adherents [3]. Thus while trophoblast probably engages in a diverse range of intercellular adhesive contacts, they have not been well characterised in relation to the presence of adhesion molecules. Functional studies are scanty, largely because in vitro culture systems have failed to reconstitute the polarised intercellular interactions of the placental tissue environment. In the present review we summarise current knowledge of adhesion systems in normal villous trophoblast.

\section{Integrins and adhesion to extracellular matrix}

Increasingly, as gestation progresses, STB adheres directly to the basement membrane (Figure 1b). This provides adhesive and structural support for the trophoblast 
epithelium throughout gestation. It contains collagen IV, heparan sulphate proteoglycan and several laminin isoforms: 511, 521 and 411, with lesser amounts of 411, 211 and 221 [7]. Integrin $\alpha 6 \beta 4$ is present at the basal surface of CTB throughout pregnancy $[8,9]$ and also at the basal syncytial surface. Integrin $\alpha 6 \beta 4$ binds laminins 511 and 521 [10] and this interaction is likely to be important in stabilising trophoblast adhesion. Basal adhesion of trophoblast is likely to regulate cell polarity, impacting on transport and barrier functions, as well as controlling cellular differentiation into fusogenic derivatives.

In addition to mediating adhesion, integrin $\alpha 6 \beta 4$ occupancy can confer resistance to apoptotic stimuli by Rac-Pak1 signalling, leading to activation of NF-kB [11]. Signalling through $\alpha 6 \beta 4$ can activate the protein tyrosine phosphatase SHP-2, in turn activating the phosphatidylinositol 3-kinase/Akt pathway $[12,13]$, which is important in CTB proliferation in the placental villus $[14,15]$.

It is remarkable that integrins of the $\beta 1$ family appear not to be expressed in first trimester villous CTB, perhaps the only nucleated cell not to bear $\beta 1$. The subunit appears, initially weakly, in the second trimester along with potential partner chains, especially $\alpha 3$ [8]. In the second and third trimester, integrins of the $\beta 1$ family probably contribute to adhesion of the villous trophoblast to ligands including laminin and collagen IV in the basement membrane. Adhesion and repair of trophoblast at sites of damage with local fibrinoid deposition may require a distinct repertoire of integrins but this has not been characterised.

The tetraspanin CD151, which associates with integrins $\alpha 6 \beta 4$ and $\alpha 3 \beta 1$, is highly expressed in villous tissue [16] at the CTB cell surface and on the apical synctial MVM. It can regulate the motility of cells on laminin as well as integrin internalisation kinetics [17]. Another member of the family, tetraspanin 6 , is highly expressed in term villous trophoblast, with lower levels in first trimester [16].

Integrin $\alpha 5 \beta 1$ is upregulated in primary cultured CTB, suggesting gene suppression in the villous environment. Cell culture studies have shown that integrin $\beta 1$ in trophoblast has 
a higher than expected molecular mass due to the presence of additional, or longer, polylactosamine chains [18]. A surprising finding is the presence of substantial amounts of $\beta 1$ integrin in the syncytial MVM at term, with partner subunits $\alpha 3, \alpha 5$ and $\alpha$ IIb $[8,19]$. Since there is no adhesion of this surface to extracellular matrix or another cell type, another explanation must be sought. One possibility could be that integrins are involved in the formation of syncytial bridges. Another is their possible involvement in a membrane complex with an additional function in the syncytium - for example, association with the amino acid transporter subunit CD98 has been demonstrated, and this in turn interacts with CD147/basigin/EMMPRIN, an MMP activator. A further possibility is that integrins are used in some way by phagocytes active in the sequestration of membrane-bounded particulate material, which is known to be shed in large quantities from the MVM into the maternal circulation $[20,21]$. The $\alpha$ IIb subunit has been identified as a substrate for cross-linking by tissue transglutaminase (tTG), which is hypothesised to process membrane proteins into aggregates for shedding [21]. A final hypothesis is that the syncytial MVM is a kind of 'sink' for superfluous membrane material arising following fusion of CTB.

Integrin $\alpha v$ and $\beta 3$ subunits are found in the MVM, and the complex $\alpha v \beta 3$ retains binding affinity for the plasma protein vitronectin and RGD peptides [22]. Another $\alpha \mathrm{V} \beta 3$ ligand, osteopontin, is expressed by both CTB and STB $[13,22]$. The $\alpha$ V subunit is a substrate for tTG action [21]. $\alpha v$ is associated with all CTB surfaces and the basal STB surface [16]. Another $\alpha \mathrm{v}$ partner subunit, $\beta 5$, is prominently expressed in first trimester tissue at trophoblast cell surfaces but not including the basal membrane; by term it is confined to CTB $[16,23]$.

\section{Cadherins, protocadherins and catenins}

\section{Overview}

The cadherin superfamily is highly diverse, with more than 100 different members. They are transmembrane glycoproteins that share cadherin sequence repeats of about 110 
amino acids. They mediate cell-cell interaction by calcium-dependent homotypic or heterotypic binding. Several subgroups have been defined: the classical (type I) and closely related type II cadherins, desmosomal cadherins, and protocadherins. Classical cadherins mostly mediate homotypic adhesions between adjacent cells and the cytoplasmic domain of classical cadherins interacts directly with p120 catenin and $\beta$-catenin. $\beta$-catenin in turn binds $\alpha$-catenin, which may link the complex to the actin cytoskeleton both directly through interaction with actin filaments and indirectly through the actin-binding proteins vinculin, zonula occludens-1 (ZO-1), $\alpha$-actinin and afadin [24]. Other actin-associated proteins such as Rho-family GTPases, Vasp, Arp2/3 and spectrin have been shown to localize at adherens junctions, and p120-catenin regulates cell motility through the actin cytoskeleton by interacting with Rho family GTPases. $\beta$-catenin signalling is important in the Wnt pathway, which is required for trophoblast differentiation [24]. Moreover, $\alpha, \beta$ and p120-catenin levels decline in vitro as CTB fuse, consistent with the declining area of cell interfaces [25].

Amongst nonclassical cadherins, cadherin 11 is expressed in syncytiotrophoblast. Its overexpression in JEG choriocarcinoma cells increases both multinucleation and differentiation, as monitored by expression of chorionic gonadotrophin (CG) $\beta$ subunit [26]. Cadherin 6 (K-cadherin) is present in first trimester villous STB, but is absent from CTB [16].

The protocadherin family contains genes with a very large number of exons encoding "variable" extracellular domains, and three exons encoding "constant" intracellular domains; combinations of extracellular and intracellular domains could be assembled potentially to generate thousands of different protocadherins. There is little available information relating to localization or function of this family in placenta, but mRNA encoding numerous members is retrievable from tissue and there is tentative immunochemical evidence for the presence of protocadherins $11,19, \alpha 12$ and $\alpha 13$ in villous trophoblast. Protocadherins $\alpha 12$ and $\alpha 13$ are described at the CTB-STB interface as well as in stromal and endothelial cells, while protocadherin 9 immunoreactivity is seen at the syncytial microvillous membrane [16]. 


\section{Classical cadherins}

E-cadherin (cadherin-1), normally found connecting neighbouring epithelial cells, occurs at CTB-CTB and CTB-STB interfaces in the villus [27-29]. Its distribution appears fairly even at the light microscopic level and there are no ultrastructurally prominent adherens-type specialisations at either interface other than desmosomes, though slight thickenings are visible of the lateral and apical CTB plasma membranes (Figure 2b). Although the significance of these thickenings is unclear, they may represent sites of adhesion molecule clustering. E-cadherin is also seen, albeit at a much lower level, in the syncytial MVM, where it has been shown to mediate binding of the pathogen Listeria monocytogenes [30].

$\mathrm{N}$-cadherin (cadherin-2) and R-cadherin (cadherin-4) are absent from placenta but Pcadherin (cadherin-3) is so called because it was originally identified from mouse placental cDNA. Early reports specified low expression in human placenta [31], although P-cadherin is detectable where trophoblasts adjoin (CTB-CTB and CTB-STB) in the first trimester villus [16], with some immunoreactivity still detectable at term [32]. VE-cad (cadherin-5) has a similar distribution [16]. Curiously, both molecules appear also at the basal syncytial plasma membrane at term; this is not always the case [28] and it is possible that this observation reflects the presence of thin lateral extensions from sparse CTB cell bodies that appear more prominent in thick sections viewed by fluorescence microscopy, and may engage in adhesions with syncytium or one another [5], but this requires further investigation. Localisation of both these cadherins is consistent with a functional role in trophoblast adhesion.

\section{Desmosomes}

Desmosomes are found at CTB-CTB as well as CTB-STB interfaces [33] (Figure 2b). In addition they are seen at syncytial bridges [3], and remnants of membranes bearing 
desmosomes have been described at the MVM border [34, 35]. In villous trophoblast, fine bundles of cytoplasmic intermediate filaments are evident at desmosomes (Figure 3a). Intermediate filament expression is from the cytokeratin family, with abundant keratins 7,8 , 18 and 19 and lower quantities of keratins 13 and $17[16,36]$.

Desmosomal plasma membrane proteins (desmocollins and desmogleins) are members of the cadherin superfamily but have cytoplasmic regions that differ from the classical cadherins, allowing the recruitment of plakoglobin ( $\gamma$-catenin), desmoplakin, and plakophilin (but not $\beta$-catenin) that form links to the intermediate filament cytoskeleton. There are three subtypes of desmocollins and desmogleins, which are expressed in a tissueand differentiation-specific manner. Desmosomal cadherins form heterotypic interactions, in contrast to the homotypic interactions of classical cadherins. Desmosomal cadherins can initiate and maintain cell-cell adhesion in the absence of classical cadherins, but adherens junctions containing classical cadherins are generally assembled before desmosomes in development. Desmogleins 2 and 3 are expressed at CTB-CTB and CTB-STB interfaces and, interestingly, can also be found at the syncytial microvillous border where only desmosome remnants have been observed [16]. mRNA encoding desmocollins 2 and 3 has been detected in human placenta [37].

Antibodies to desmoplakin I/II, a protein associated with the desmosomal dense plaque, are widely used to locate trophoblast-trophoblast interfaces in vivo [38] and in vitro [39]; the typically linear punctate distribution provides good evidence for unfused cell borders. Plakoglobin, also known as desmoplakin III, which can associate with cadherincatenin complexes as well as desmosomes, shows a similar distribution in the villus. Related immunoreactivity is also seen at the syncytial microvillous membrane [16]. Other plakin protein family members whose mRNA has been detected in placenta include plectin 1 and dystonin 1 (BPAG1); however their distribution has not been mapped. Similarly, mRNAs encoding the desmosomal plaque proteins plakophilins 1-4 are all present in placental libraries. 


\section{Nectins}

Nectins are calcium-independent transmembrane immunoglobulin-like cell-cell adhesion molecules which associate with cadherins to form adherens junctions (AJs) in epithelial cells and fibroblasts [40, 41]. Nectin-1 and -3 most strongly trans-interact, mediating cell-cell adhesion. Afadin, which is recruited to the catenin/cadherin complex, is an actin filament-binding protein that connects nectin to the cytoskeleton. Nectin 3, which binds nectin 1, is found in villous trophoblast [16]. Nectin 4 also binds nectin 1 and is expressed in human placenta [42] but reports suggest it is expressed by endothelial cells and not trophoblast.

\section{Tight junction proteins}

Tight junctions (TJ) or zonulae occludentes, which regulate the paracellular pathway for the movement of ions and solutes, contain the transmembrane proteins occludin and claudin, and the cytoplasmic scaffolding proteins ZO-1, -2, and -3 which link to the actin cytoskeleton. ZO-1 is peripheral to the tight junction and can also associate with adherens junctions. It is by no means clear why such junctions are required in the placenta, where a continuous syncytium regulates solute transfer between maternal and fetal tissues (Figure 1). Nonetheless, immunoreactive TJ proteins including occludin and ZO-1 are present at CTB-CTB interfaces, CTB-STB interfaces and in the syncytial MVM [43, 44]. TEM studies demonstrate the presence of TJ-like structures at syncytial bridges [3], (Figure 3b). Claudin 1 marks prominently the lateral interfaces between CTB, and those between CTB and STB in the first trimester [16]. Claudin 3 immunoreactivity is seen in trophoblast, while claudin 4 is found in the syncytial microvillous membrane and villous CTB in first trimester and term tissue [16]. Occludin but not ZO-1 is found in first trimester villous trophoblast populations [45]. Continuous staining suggests true tight junctions are not present. 


\section{Gap junctions}

Gap junctions contain transmembrane channels composed of connexin (Cx) dodecamers that mediate cell-to-cell communication via the diffusion of small signalling molecules such as CAMP, cGMP, inositol triphosphate (IP3) and $\mathrm{Ca}^{2+}$. Connexin 43 is present at the CTB-STB interface where immunochemical visualization reveals a punctate array consistent with the presence of gap junctions. The same connexin is also present at CTBCTB interfaces [46]. In early villous tissue there is evidence for connexin 40 [43]. Altered trophoblast structure and function in connexin-deficient mice [37], and in vitro evidence (see section 9) suggest the likelihood that gap junctional communication may be a prerequisite of villous trophoblast differentiation.

\section{Ephrins}

Ephrins are ligands for Eph receptors, which constitute the largest subfamily of receptor tyrosine kinases. These receptors bind membrane-associated ephrin ligands on neighboring cells and mediate short-range cell-to-cell communication [47]. Ephrin A2 shows widespread expression in all placental cells including trophoblast [16]. Ephrin B2 is found in first trimester villous trophoblast but by term its expression is confined to vascular endothelium. Its receptor Eph B4 is prominent in the first trimester syncytial MVM, with reduced amounts evident at term [48].

\section{Glycan-based adhesion}

Siglec-6 is a member of a family of sialic acid-binding lectins [49], one ligand for which is sialyl Tn (Neu5Aca2,6-GalNAca-). The role of siglecs appears to be in negative regulation of cellular signalling. Siglec-6 immunolocalises to the syncytial MVM in human term placenta [50]. Though lectin histochemistry has suggested that human term placenta has rather low levels of terminal $\alpha 2,6$-linked sialic acid, showing more $\alpha 2,3$-linkages [51], trophoblast (including the extravillous population) does contain glycoproteins with siglec- 6 
recognition capacity. Siglec- 6 also binds leptin [50]; thus, the siglec- 6 binding site in villous trophoblast may be occupied by cis-ligands.

Trophinin, a novel cell surface-associated glycoprotein with mucin-like properties mediates homotypic adhesion of trophoblast to endometrial epithelial cells during implantation $[52,53]$. Tropinin forms a heterotrimeric complex with tastin, a cytoplasmic protein, and bystin, a cytoplasmic bridging protein. Immunohistochemical studies have shown that trophinin and bystin are expressed in the cytoplasm of villous STB and in decidual cells at the utero-placental interface at 6 weeks gestation, whereas tastin is expressed on the apical side of STB. At 10 weeks, trophinin and bystin expression was maintained in villous CTB, but tastin expression could not be detected. Beyond this time, expression of all three proteins decreased and disappeared from placental villi.

Ligation of trophinin leads to tyrosine phosphorylation and actin reorganisation in trophoblast. Following trophinin-mediated cell adhesion, bystin is released from trophinin, allowing the activation of ErbB4 protein tyrosine kinase, which promotes trophoblast proliferation and motility $[53,54]$.

\section{Fusion during trophoblast differentiation}

In one phase of the life cycle of villous trophoblast there is stable CTB-STB adhesion while, at a later stage, fusion occurs between a CTB and the overlying syncytium [55] (Figure 4a). In vitro, primary term CTB leave the cell cycle, differentiate and fuse within 3 days, indicating that enzymatic dissociation of normal trophoblasts produces an immediate step change in state with uncontrolled progression to terminal differentiation [56]. Gap junctional communication seems to be important in trophoblast fusion, which is impaired in primary CTB after Cx43 knockdown [46]. Other suggested membrane components implicated in fusion are syncytins, ADAMs (a disintegrin and metalloproteases), exposed annexin A5 and exposed (flipped) phosphatidylserine [55]. Syncytins are envelope (env) glycoproteins originating from viral sequences incorporated into the human genome. The 
knockdown of HERV-W env glycoprotein, encoding the endogenous retroviral envelope glycoprotein syncytin 1, reduces fusion of primary CTB in vitro [57], and ectopic expression of either HERV-W or HERV-HRD (syncytin 2) can promote fusion [58, 59]. Cadherin 11 similarly increases fusion in a trophoblast cell line [26]. ADAM genes encode type-1 transmembrane proteins with a unique domain structure composed of a signal sequence and domains including prometalloprotease, disintegrin, cysteine-rich, EGF-like, transmembrane and cytoplasmic. Over 30 ADAM family members have been identified [60]. ADAM17, also known as tumour necrosis factor-a converting enzyme (TACE), is a protease required for shedding active TNF- $\alpha$ from the cell surface by cleaving pro-TNF- $\alpha$. ADAM17 is localized at CTB-CTB and CTB-STB interfaces in first trimester placental villi. Some immunoreactivity is also found at the syncytial MVM [16]. At term these deposits remain and the basal syncytial surface also appears immunoreactive. ADAMTSL4, a disintegrin and metalloproteinase with thrombospondin motifs, is a protein with seven thrombospondin type 1 repeats, strongly immunoreactive in first trimester syncytium and associated with syncytial knots at term [16]. ADAM12 mRNA is highly represented in placental cDNA libraries. The protein has been proposed as a mediator of fusion [55]. It has been shown to compensate for the dystrophin deficiency in $m d x$ mice by redistribution of components of muscle cell-adhesion complexes [61]. It has also been found in giant cell tumours of bone formed by the fusion of mononuclear stromal cells [62].

\section{Conclusion}

Cell contact, and the signalling events that follow, together play a profound role in the maintenance of epithelial integrity and control of cell growth and fusion in the villous environment. A better understanding of the role of intercellular adhesion in trophoblast function will depend on the development of approaches that avoid destroying the intercellular contacts upon which cell behaviour critically depends. Explant cultures in which 
direct mRNA or protein targeting can be used with preservation of intercellular relationships offer promise for the future. 


\section{References}

[1] Jones CJ, Fox H. Ultrastructure of the normal human placenta. Electron Microsc Rev $1991 ; 4: 129-78$.

[2] Jones C], Fox $\mathrm{H}$. Syncytial knots and intervillous bridges in the human placenta: an ultrastructural study. J Anat 1977;124:275-86.

[3] Metz J, Weihe E, Heinrich D. Intercellular junctions in the full term human placenta. I. Syncytiotrophoblastic layer. Anat Embryol (Berl) 1979;158:41-50.

[4] Mayhew TM, Barker BL. Villous trophoblast: morphometric perspectives on growth, differentiation, turnover and deposition of fibrin-type fibrinoid during gestation. Placenta 2001;22:628-38.

[5] Jones CJ, Harris LK, Whittingham J, Aplin JD, Mayhew TM. A Re-appraisal of the Morphophenotype and Basal Lamina Coverage of Cytotrophoblasts in Human Term Placenta. Placenta 2007.

[6] Kaufmann P, Huppertz B, Frank HG. The fibrinoids of the human placenta: origin, composition and functional relevance. Ann Anat 1996;178:485-501.

[7] Church H, Richards A, Aplin J. Laminins in decidua, placenta and choriocarcinoma cells. . Trophoblast Research 1996;10:143-62.

[8] Korhonen M, Ylanne J, Laitinen L, Virtanen I. The alpha 1-alpha 6 subunits of integrins are characteristically expressed in distinct segments of developing and adult human nephron. J Cell Biol 1990;111:1245-54.

[9] Aplin JD. Expression of integrin alpha 6 beta 4 in human trophoblast and its loss from extravillous cells. Placenta 1993;14:203-15.

[10] Nishiuchi R, Takagi J, Hayashi M, Ido H, Yagi Y, Sanzen N, Tsuji T, Yamada M, Sekiguchi K. Ligand-binding specificities of laminin-binding integrins: a comprehensive survey of laminin-integrin interactions using recombinant alpha3beta1, alpha6beta1, alpha7beta1 and alpha6beta4 integrins. Matrix Biol 2006;25:189-97.

[11] Friedland JC, Lakins JN, Kazanietz MG, Chernoff J, Boettiger D, Weaver VM. alpha6beta4 integrin activates Rac-dependent p21-activated kinase 1 to drive NFkappaB-dependent resistance to apoptosis in 3D mammary acini. J Cell Sci 2007; 120:3700-12.

[12] Merdek KD, Yang X, Taglienti CA, Shaw LM, Mercurio AM. Intrinsic signaling functions of the beta4 integrin intracellular domain. J Biol Chem 2007;282:30322-30.

[13] Folgiero V, Bachelder RE, Bon G, Sacchi A, Falcioni R, Mercurio AM. The alpha6beta4 integrin can regulate ErbB-3 expression: implications for alpha6beta4 signaling and function. Cancer Res 2007;67:1645-52.

[14] Forbes K, Westwood M. The IGF axis and placental function. a mini review. Horm Res 2008;69:129-37.

[15] Forbes K, Westwood M, Baker PN, Aplin JD. Insulin-like growth factor-I and -II regulate the life cycle of trophoblast in the developing human placenta. Am J Physiol Cell Physiol 2008.

[16] The human protein atlas. http://www.proteinatlas.org/.

[17] Winterwood NE, Varzavand A, Meland MN, Ashman LK, Stipp CS. A critical role for tetraspanin CD151 in alpha3beta1 and alpha6beta4 integrin-dependent tumor cell functions on laminin-5. Mol Biol Cell 2006;17:2707-21.

[18] Moss L, Prakobphol A, Wiedmann TW, Fisher SJ, Damsky CH. Glycosylation of human trophoblast integrins is stage and cell-type specific. Glycobiology 1994;4:567-75.

[19] Divers MJ, Bulmer JN, Miller D, Lilford RJ. Beta 1 integrins in third trimester human placentae: no differential expression in pathological pregnancy. Placenta $1995 ; 16: 245-60$.

[20] Redman CW, Sargent IL. Microparticles and immunomodulation in pregnancy and pre-eclampsia. J Reprod Immunol 2007;76:61-7. 
[21] Robinson NJ, Baker PN, Jones CJ, Aplin JD. A role for tissue transglutaminase in stabilization of membrane-cytoskeletal particles shed from the human placenta. Biol Reprod 2007;77:648-57.

[22] Vanderpuye OA, Labarrere CA, McIntyre JA. A vitronectin-receptor-related molecule in human placental brush border membranes. Biochem J 1991;280 ( Pt 1):9-17.

[23] Zhou Y, Fisher SJ, Janatpour M, Genbacev O, Dejana E, Wheelock M, Damsky CH. Human cytotrophoblasts adopt a vascular phenotype as they differentiate. A strategy for successful endovascular invasion? J Clin Invest 1997;99:2139-51.

[24] Hartsock A, Nelson WJ. Adherens and tight junctions: Structure, function and connections to the actin cytoskeleton. Biochim Biophys Acta 2008;1778:660-9.

[25] Getsios S, Chen GT, MacCalman CD. alpha-, beta-, gamma-catenin, and p120(CTN) expression during the terminal differentiation and fusion of human mononucleate cytotrophoblasts in vitro and in vivo. Mol Reprod Dev 2001;59:168-77.

[26] Getsios S, MacCalman CD. Cadherin-11 modulates the terminal differentiation and fusion of human trophoblastic cells in vitro. Dev Biol 2003;257:41-54.

[27] Coutifaris C, Kao LC, Sehdev HM, Chin U, Babalola GO, Blaschuk OW, Strauss JF, 3rd. $\mathrm{E}$-cadherin expression during the differentiation of human trophoblasts. Development 1991;113:767-77.

[28] Brown LM, Lacey HA, Baker PN, Crocker IP. E-cadherin in the assessment of aberrant placental cytotrophoblast turnover in pregnancies complicated by pre-eclampsia. Histochem Cell Biol 2005;124:499-506.

[29] Vicovac L, Aplin JD. Epithelial-mesenchymal transition during trophoblast differentiation. Acta Anat (Basel) 1996;156:202-16.

[30] Lecuit M, Nelson DM, Smith SD, Khun H, Huerre M, Vacher-Lavenu MC, Gordon JI, Cossart P. Targeting and crossing of the human maternofetal barrier by Listeria monocytogenes: role of internalin interaction with trophoblast E-cadherin. Proc Natl Acad Sci U S A 2004;101:6152-7.

[31] Shimoyama Y, Yoshida T, Terada M, Shimosato Y, Abe O, Hirohashi S. Molecular cloning of a human Ca2+-dependent cell-cell adhesion molecule homologous to mouse placental cadherin: its low expression in human placental tissues. J Cell Biol 1989;109:1787-94.

[32] Balaram P, Alex S, Panikkar B, Rajalekshmi TN. Adhesion-related proteins E-cadherin, $\mathrm{P}$-cadherin, CD44, and CD44v6, and antimetastatic protein $\mathrm{nm} 23 \mathrm{H} 1$ in complete hydatidiform moles in relation to invasion potential. Int $\mathrm{J}$ Gynecol Cancer 2004;14:532-9.

[33] Metz J, Weihe E. Intercellular junctions in the full term human placenta. II. Cytotrophoblast cells, intravillous stroma cells and blood vessels. Anat Embryol (Berl) 1980;158:167-78.

[34] Enders AC. Formation of Syncytium from Cytotrophoblast in the Human Placenta. Obstet Gynecol 1965;25:378-86.

[35] Carter JE. Morphologic Evidence of Syncytial Formation from the Cytotrophoblastic Cells. Obstet Gynecol 1964;23:647-56.

[36] Muhlhauser J, Crescimanno C, Kasper M, Zaccheo D, Castellucci M. Differentiation of human trophoblast populations involves alterations in cytokeratin patterns. J Histochem Cytochem 1995;43:579-89.

[37] Zheng-Fischhofer $Q$, Kibschull $M$, Schnichels $M$, Kretz $M$, Petrasch-Parwez $E$, Strotmann J, Reucher H, Lynn BD, Nagy JI, Lye SJ, Winterhager E, Willecke K. Characterization of connexin31.1-deficient mice reveals impaired placental development. Dev Biol 2007;312:258-71.

[38] Beham A, Denk H, Desoye G. The distribution of intermediate filament proteins, actin and desmoplakins in human placental tissue as revealed by polyclonal and monoclonal antibodies. Placenta 1988;9:479-92. 
[39] Douglas GC, King BF. Differentiation of human trophoblast cells in vitro as revealed by immunocytochemical staining of desmoplakin and nuclei. J Cell Sci 1990;96 ( Pt 1): $131-41$.

[40] Takai Y, Nakanishi H. Nectin and afadin: novel organizers of intercellular junctions. ] Cell Sci 2003;116:17-27.

[41] Nakanishi $H$, Takai $Y$. Roles of nectins in cell adhesion, migration and polarization. Biol Chem 2004;385:885-92.

[42] Reymond N, Fabre S, Lecocq E, Adelaide J, Dubreuil P, Lopez M. Nectin4/PRR4, a new afadin-associated member of the nectin family that trans-interacts with nectin1/PRR1 through V domain interaction. J Biol Chem 2001;276:43205-15.

[43] Challier JC, Dubernard G, Galtier M, Bintein T, Vervelle C, Raison D, Espie MJ, Uzan $\mathrm{S}$. Junctions and adhesion molecules in first trimester and term human placentas. Cell Mol Biol (Noisy-le-grand) 2005;51 Suppl:OL713-22.

[44] Marzioni D, Banita M, Felici A, Paradinas FJ, Newlands E, De Nictolis M, Muhlhauser J, Castellucci M. Expression of ZO-1 and occludin in normal human placenta and in hydatidiform moles. Mol Hum Reprod 2001;7:279-85.

[45] Leach L, Lammiman MJ, Babawale MO, Hobson SA, Bromilou B, Lovat S, Simmonds MJ. Molecular organization of tight and adherens junctions in the human placental vascular tree. Placenta 2000;21:547-57.

[46] Malassine A, Cronier L. Involvement of gap junctions in placental functions and development. Biochim Biophys Acta 2005;1719:117-24.

[47] Palmer A, Klein R. Multiple roles of ephrins in morphogenesis, neuronal networking, and brain function. Genes Dev 2003;17:1429-50.

[48] Chennakesava CS, Di Santo S, Ziemiecki A, Schneider H, Andres AC. Differential expression of the receptor tyrosine kinase EphB4 and its ligand Ephrin-B2 during human placental development. Placenta 2006;27:959-67.

[49] Crocker PR, Paulson JC, Varki A. Siglecs and their roles in the immune system. Nat Rev Immunol 2007;7:255-66.

[50] Brinkman-Van der Linden EC, Hurtado-Ziola N, Hayakawa T, Wiggleton L, Benirschke K, Varki A, Varki N. Human-specific expression of Siglec-6 in the placenta. Glycobiology 2007;17:922-31.

[51] Jones CJ, Carter AM, Aplin JD, Enders AC. Glycosylation at the fetomaternal interface in hemomonochorial placentae from five widely separated species of mammal: is there evidence for convergent evolution? Cells Tissues Organs 2007;185:269-84.

[52] Suzuki N, Nakayama J, Shih IM, Aoki D, Nozawa S, Fukuda MN. Expression of trophinin, tastin, and bystin by trophoblast and endometrial cells in human placenta. Biol Reprod 1999;60:621-7.

[53] Sugihara K, Sugiyama D, Byrne J, Wolf DP, Lowitz KP, Kobayashi Y, Kabir-Salmani M, Nadano D, Aoki D, Nozawa S, Nakayama J, Mustelin T, Ruoslahti E, Yamaguchi N, Fukuda MN. Trophoblast cell activation by trophinin ligation is implicated in human embryo implantation. Proc Natl Acad Sci U S A 2007;104:3799-804.

[54] Fukuda MN, Sugihara K. Signal transduction in human embryo implantation. Cell Cycle 2007;6:1153-6.

[55] Huppertz B, Bartz C, Kokozidou M. Trophoblast fusion: fusogenic proteins, syncytins and ADAMs, and other prerequisites for syncytial fusion. Micron 2006;37:509-17.

[56] Aplin JD, Crocker IP. In vitro models for studying pre-eclampsia. In: Lyall F, Belfort M (eds.), Pre-eclampsia: etiology and clinical practice. Cambridge: Cambridge University Press; 2007: 37-49.

[57] Frendo JL, Olivier D, Cheynet V, Blond JL, Bouton O, Vidaud M, Rabreau M, EvainBrion D, Mallet F. Direct involvement of HERV-W Env glycoprotein in human trophoblast cell fusion and differentiation. Mol Cell Biol 2003;23:3566-74. 
[58] Potgens AJ, Drewlo S, Kokozidou M, Kaufmann P. Syncytin: the major regulator of trophoblast fusion? Recent developments and hypotheses on its action. Hum Reprod Update 2004;10:487-96.

[59] Mangeney M, Renard M, Schlecht-Louf G, Bouallaga I, Heidmann O, Letzelter C, Richaud A, Ducos B, Heidmann T. Placental syncytins: Genetic disjunction between the fusogenic and immunosuppressive activity of retroviral envelope proteins. Proc Natl Acad Sci U S A 2007;104:20534-9.

[60] Mochizuki S, Okada Y. ADAMs in cancer cell proliferation and progression. Cancer Sci 2007;98:621-8.

[61] Moghadaszadeh B, Albrechtsen R, Guo LT, Zaik M, Kawaguchi N, Borup RH, Kronqvist $P$, Schroder HD, Davies KE, Voit T, Nielsen FC, Engvall E, Wewer UM. Compensation for dystrophin-deficiency: ADAM12 overexpression in skeletal muscle results in increased alpha 7 integrin, utrophin and associated glycoproteins. Hum Mol Genet 2003; 12:2467-79.

[62] Tian BL, Wen JM, Zhang M, Xie D, Xu RB, Luo CJ. The expression of ADAM12 (meltrin alpha) in human giant cell tumours of bone. Mol Pathol 2002;55:394-7. 


\section{Figure legends}

Figure 1: Semithin $0.5 \mu \mathrm{m}$ sections of human placenta. a) First trimester villus showing a continuous layer of CTB underlying the syncytium. Note the cell undergoing mitosis indicating CTB proliferation $\left(^{*}\right)$. Capillaries and a light extracellular matrix occupy the stroma. b) At term, CTB cells (c) are sparse and the STB has thinned over the capillaries to maximise diffusion of gases. Cell adhesion is required between CTB (arrowheads), CTB and STB (double arrows), basal lamina and trophoblast basal plasma membrane (arrow). Toluidine blue.

Figure 2: a) Bridge formed between two term villi, showing alkaline phosphatase activity between the two apposing membranes. b) Desmosomes (D) between CTB cells and CTB and STB in first trimester placenta. Dense thickenings towards the apical surfaces of the CTB cells can be seen - see insets for enlargements. Insets - a thickening (small arrows) of the apical plasma membrane adjoining the desmosome is also present.

Figure 3: a) High power micrograph of desmosomes (D) between term CTB- and STB showing intermediate filaments (IF) extending out from the junction. b) Second trimester placenta, 18 weeks gestation. A tight junction-like structure (TJ) can be seen on the apical surface of the STB, together with the remnants of a desmosome (D) and focal densities (FD) that may represent remnants of former desmosomes.

Figure 4: Term CTB fusing with the syncytium, shown by alkaline phosphatase activity of the membranes. The point from which fusion is progressing can clearly be seen (arrow). 